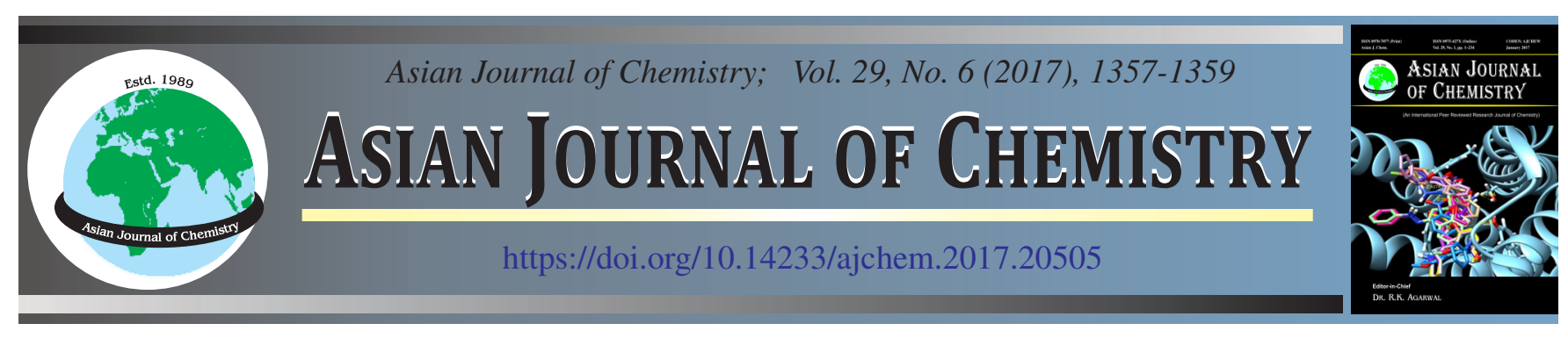

\title{
Synthesis and Characterization of Impurities in Rasagiline: A Novel MAO-B Inhibitor in Parkinson's Disease Therapy
}

\author{
N. Maruthi Raju ${ }^{1,2, *}$ J. Moses Babu ${ }^{1}$ and B. Venkateswara RaO ${ }^{2}$
}

${ }^{1}$ Custom Pharmaceutical Services, Dr. Reddy's Laboratories Limited, Bollaram Road, Miyapur, Hyderabad-500 049, India ${ }^{2}$ Department of Organic Chemistry, Food, Drugs and Water, Andhra University, Visakhapatnam-530 003, India

*Corresponding author: E-mail: raju1001@gmail.com

Received: 10 January 2017;

Accepted: 31 March 2017;

Published online: 10 April 2017;

AJC-18354

\begin{abstract}
Rasagiline (1) is indicated as adjunctive therapy and monotherapy for treatment of Parkinson's disease approved by the FDA. During the process development of rasagiline, few processes related impurities were observed along with the final API. These impurities were identified as indanol (2), indanamine (3), allyl (4), keto (7), other isomer (6) and chloro allyl (5,5a) impurities. The present work describes the synthesis of all these impurities and characterized by ${ }^{1} \mathrm{H}$ NMR and Mass spectral analysis.
\end{abstract}

Keywords: 1-Indanone, $N$-(prop-2-yn-1-yl)-2,3-dihydro-1H-inden-1-amine, Allyl bromide, Propargylamine hydrochloride.

\section{INTRODUCTION}

Among the various health problems, Parkinson's disease are very critical one and eternal decadent disorder of the central nervous system that probably influence the motor system [1]. Human cell having two forms of monoamine oxidase (MAO), which are MAO-A and MAO-B in the brain, but MAO-B is far most frequent and is responsible for the disruption of dopamine after its discharge into the synapse. Rasagiline [IUPAC: R-(+)-N-propargyl-1-aminoindan (Fig. 1), [m.f. $\mathrm{C}_{12} \mathrm{H}_{13} \mathrm{~N}$ and m.w. 171.23] avoids the disruption of dopamine by unreversible binding to MAO-B. So dopamine is respectively more available, somehow balancing for the decreased quantities made in the brains of humans with Parkinsons [2].

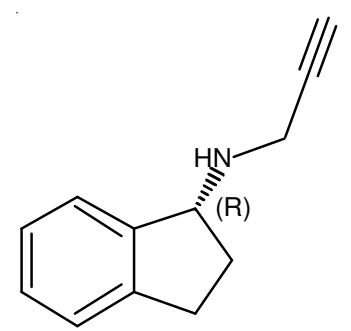

Fig. 1. Chemical structure of rasagiline

Drugs playing a prominent role in human life to fight various diseases. Unlike earlier days, most of the drugs currently are purely synthetically made. Unambiguously, the prepared drugs contain different impurities like chemicals or microbes.
Most of the impurities are chemicals only. Impurities are additional compounds those are not the drug substance [also called as the active ingredient or the active pharmaceutical ingredient (API)], but rise while the synthesis, storage of the drug, extraction or purification. Knowing the source, prevail and quantification of impurities are critical to the preparation of good quality drug substances.

The consumption of medicines can lead to antagonistic effects, which in the maximum of cases, are relevant to the entry of various impurities and substances that take place in the remedy moreover the pharmacologically active ingredients into the body. Impurities can have a strong antagonistic effect due to unacceptable toxicological and pharmacological action, which can control over the certain effect of the medicine. Also impurities can prevent the effect of the pharmaceutical properties of the drug substance [3].

The potential impurities in a drug substance (API) can have a important impact on the safety and quality of the drug substance. The percentage of impurities in any drug substance are represented as per its toxicological or biological data. It is quite significant for "regulatory" aspect of drug substance approval also to provide limits of "relevant impurities". Therefore, it is mandatory to study the impurities of any drug substance and prevail it while manufacturing of a drug substance. As per the ICH guidelines, any impurity which is forming at equal/more than $0.10 \%$ with respect to the drug substance should be synthesized, identified and characterized exhaustively [4]. 
There are several methods to synthesize rasagiline. In all methods, some common process related impurities like 1-indanol, 1-indanamine, allyl impurity, chloro allyl impurity, $S$-isomer and keto impurity. 1-Indanol is commercially available; remaining impurities synthesized and characterized by ${ }^{1} \mathrm{H}$ NMR and Mass spectral analysis.

\section{EXPERIMENTAL}

All reactions were carried out in oven-dried glassware $\left(120^{\circ} \mathrm{C}\right)$ under an atmosphere of nitrogen. Acetonitrile, chloroform and acetone were purchased from Merck Inc. $\mathrm{N}$-Bromosuccinimide (NBS), azobisisobutyronitrile (AIBN), propargylamine hydrochloride and Lindlar catalyst were purchased from Aldrich Chemical Co.

Analytical thin layer chromatography (TLC) was performed on precoated plates (silica gel 60 F-254), which were purchased from Merck Inc. Purification by gravity column chromatography was carried out by use of silicycle ultrapure silica gel (particle size 40-63 $\mu \mathrm{m}, 230-400$ mesh). Proton NMR spectra were obtained on a Varian Mercury-400 (400 MHz) spectrometer by use of chloroform- $d\left(\mathrm{CDCl}_{3}\right)$ and DMSO- $d_{6}$ as solvents.

Synthesis of 2,3-dihydro- $\mathbf{H}$-inden-1-amine or 1 -indanamine (3): To a stirred solution of 1-indanone (8) (5 g, 0.0379 mol, $1.0 \mathrm{eq})$, ammonium formate $(14.31 \mathrm{~g}, 0.227 \mathrm{~mol}, 6.0 \mathrm{eq})$ and $\mathrm{Zn}$ powder $(6.9 \mathrm{~g}, 0.113 \mathrm{~mol}, 3.0 \mathrm{eq})$ in methanol (100 $\mathrm{mL}$ ) was stirred under reflux. After completion of the reaction the mixture was filtered through celite and the solvent was removed by vacuum. The residue was treated with conc. $\mathrm{HCl}$ solution $(4 \mathrm{~mL})$ and water $(30 \mathrm{~mL})$ and then extracted with EtOAc $(2 \times 50 \mathrm{~mL})$ to remove organic residues. The aqueous phase was alkalized with ammonia solution to and extracted with EtOAc $(4 \times 40 \mathrm{~mL})$. The organic phase was washed with brine, dried over sodium sulphate and the solvent removed under vacuum resulted compound $32.75 \mathrm{~g}$ as $56 \%$ yield (80.18 \% by HPLC). ${ }^{1} \mathrm{H}$ NMR (400 MHz, $\left.\mathrm{CDCl}_{3}\right) ; \delta 7.72$ (d, 1H, Ar-H), 7.24 (m, 3H, Ar-H), $5.82(\mathrm{~d}, 1 \mathrm{H}, \mathrm{NH}), 5.58(\mathrm{~d}, 1 \mathrm{H}$, $\mathrm{NH}), 4.90$ (t, 1H, CH-NH$), 3.79$ (d, 1H, Ar- $\left.\mathrm{CH}_{2}\right), 3.65$ (d, $\left.1 \mathrm{H}, \mathrm{Ar}-\mathrm{CH}_{2}\right), 3.17$ (m, 1H, $\left.\mathrm{CH}_{2}-\mathrm{CH}\right), 2.89\left(\mathrm{~m}, 1 \mathrm{H}, \mathrm{CH}_{2}-\mathrm{CH}\right)$. Mass: $m / z$ calcd. 133.09 , found $m / z 117.0\left(\mathrm{M}-\mathrm{NH}_{2}\right)^{+}$.

Synthesis of $\mathrm{N}$-allyl-2,3-dihydro- $1 \mathrm{H}$-inden-1-amine or allyl impurity (4): A solution of $N$-(prop-2-yn-1-yl)-2,3dihydro- $1 H$-inden-1-amine (10) (10 g, $0.0584 \mathrm{~mol}, 1.0 \mathrm{eq})$, Lindlar catalyst $(1.0 \mathrm{~g}, 10 \% \mathrm{w} / \mathrm{w})$ and catalytic amount of pyridine $(0.456 \mathrm{~g}, 0.00584 \mathrm{~mol}, 0.1 \mathrm{eq})$ were taken in methanol $(100 \mathrm{~mL})$ and were hydrogenated by using hydrogen balloon pressure conditions for $6 \mathrm{~h}$ at ambient temperature. The reaction was monitored by using TLC, after completion of the reaction, the mixture was filtered through celite bed, $\mathrm{MeOH}$ was evaporated by high vacuum below $50{ }^{\circ} \mathrm{C}$. The resultant crude was titrated by using EtOAc and $n$-hexane yielded $8.5 \mathrm{~g}$ $(84.5 \%)$ compound 4 as a brown colour oil. ${ }^{1} \mathrm{H}$ NMR (400 MHz, DMSO); $\delta 7.32$ (dd, 1H, Ar-H), 7.21-7.14 (m, 3H, Ar$\mathrm{H})$, 5.93-5.86 (m, 1H, =CH), 5.23-5.03 (m, 2H, = $\left.\mathrm{CH}_{2}\right), 4.10$ (t, 1H, NH-CH), 3.60 (bs, 1H, NH) 3.29-3.22 (m, 2H, NH$\mathrm{CH}_{2}$ ), 2.89-2.69 (m, 2H, Ar- $\mathrm{CH}_{2}$ ), 2.49-2.27 (m, 2H, CH-CH ${ }_{2}$ ). Mass: $m / z$ calcd. 173.12 , found $m / z 174.1\left(\mathbf{M}^{+1}\right)$. HPLC purity (\%): 91.70 .
Synthesis of 3-bromo-2,3-dihydro-1H-inden-1-one (9): 1-Indanone (8) (10 g, $0.0758 \mathrm{~mol}, 1.0 \mathrm{eq})$ react with N-bromosuccinimide (NBS) (13.8 g, $0.0758 \mathrm{~mol} 1.0 \mathrm{eq})$ in a catalyst azobisisobutyronitrile (AIBN), was refluxed in $\mathrm{CHCl}_{3}(100$ $\mathrm{mL}$ ) solvent for $3 \mathrm{~h}$. After completion of reaction the reaction mixture was quenched with water, extracted with $\mathrm{CHCl}_{3}$, washed with water, dried over sodium sulphate and concentrated under reduced pressure to obtain the $11 \mathrm{~g}$ compound $9 .{ }^{1} \mathrm{H}$ NMR $\left(400 \mathrm{MHz}, \mathrm{CDCl}_{3}\right) ; \delta 7.70$ (dd, 3H, Ar-H), 7.47 (m, 1H, Ar-H), 5.59 (q, 1H, CH-Br), 3.34 (dd, 2H, $\mathrm{CH}_{2}-\mathrm{CO}$ ), 3.03 (dd, 1H, $\left.\mathrm{CH}_{2}-\mathrm{CO}\right)$. Mass: $\mathrm{m} / \mathrm{z}$ calcd. 211 , found $\mathrm{m} / z 212\left(\mathrm{M}^{+1}\right)^{+}$. HPLC purity (\%): 98.58 .

Synthesis of 3-(prop-2-yn-1-ylamino)-2,3-dihydro-1Hinden-1-one or keto impurity (7): A solution of compound 9 ( $5 \mathrm{~g}, 0.0235 \mathrm{~mol}, 1.0 \mathrm{eq}$ ) propargylamine hydrochloride (2.16 $\mathrm{g}, 0.0235 \mathrm{~mol}, 1.0 \mathrm{eq})$ and $\mathrm{K}_{2} \mathrm{CO}_{3}(6.50 \mathrm{~g}, 0.0472 \mathrm{~mol}, 2.0 \mathrm{eq})$ were taken in acetonitile $(50 \mathrm{~mL})$, then the reaction mixture was heated at $60{ }^{\circ} \mathrm{C}$ for $3 \mathrm{~h}$. The reaction was monitored by using TLC, after completion of the reaction, acetonitile was evaporated by high vacuum below $50{ }^{\circ} \mathrm{C}$ added EtOAc and water. Organic layer was separated dried and concentrated. The resultant crude was purified by column chromatography by using EtOAc and $n$-hexane as a mobile phase resulted 3.1 g compound 7 as a brown thick mass. ${ }^{1} \mathrm{H}$ NMR $(400 \mathrm{MHz}$, DMSO); $\delta 7.99$ (d, 1H, Ar-H), 7.80 (dd, 1H, Ar-H), 7.78-7.68 (dd, 2H, Ar-H), 5.10 (d, 1H, NH-CH), 4.12 (d, 2H, NH-CH $)$, 3.77 (s, 1H, CH),3.09 (m, 1H, CO-CH), 2.86 (dd,1H, CO$\mathrm{CH})$. Mass: $m / z$ calcd185.07, found $m / z, 186.1\left(\mathbf{M}^{+1}\right)^{+}$. HPLC purity (\%): 98.58 .

Synthesis of $(S)-N$-(prop-2-yn-1-yl)-2,3-dihydro- $1 H$ inden-1-amine or $S$-isomer (6): A solution of $N$-(prop-2-yn1-yl)-2,3-dihydro- $1 H$-inden-1-amine (10) $(60 \mathrm{~g}, 0.531 \mathrm{~mol}$, $1.0 \mathrm{eq})$, was taken in isopropyl alcohol $(300 \mathrm{~mL}, 5 \mathrm{~V})$ and methanol $(420 \mathrm{~mL}, 7 \mathrm{~V}), \mathrm{D}(-)$ tartaric acid was added and heated for $70{ }^{\circ} \mathrm{C}$ for $3 \mathrm{~h}$. The formed sold was filtered. The tartarate salt was basified by using aqueous $\mathrm{NaHCO}_{3}$ solution and extracted with EtOAc. Organic layer was dried and concentrated under vacuum yielded $28 \mathrm{~g}(42 \%)$ compound 6 as a brown thick mass. ${ }^{1} \mathrm{H}$ NMR $(400 \mathrm{MHz}, \mathrm{DMSO}) \delta 7.62(\mathrm{~d}, 1 \mathrm{H}$, Ar-H), 7.40-7.28 (m, 3H, Ar-H), 4.82-4.80 (m, 1H, NH-CH), $4.00\left(\mathrm{~s}, 2 \mathrm{H}, \mathrm{NH}-\mathrm{CH}_{2}\right), 3.78(1 \mathrm{H}$, acetyl $\mathrm{CH}), 3.15-3.07(\mathrm{~m}$, 1H, Ar-CH), 2.92-2.84 (m, 1H, Ar-CH), 2.48-2.16 (m, 2H, CH-CH${ }_{2}$ ). Mass: $\mathrm{m} / \mathrm{z}$ calcd. 171.10 , found $\mathrm{m} / \mathrm{z} 172.0\left(\mathrm{M}^{+1}\right)$. HPLC Purity (\%): 99.20. Chiral HPLC (\%): 99.70.

Synthesis of $\mathrm{N}$-(2-chloroallyl)-2,3-dihydro-1H-inden1-amine or chloro allyl impurity (5\&5a): A solution of $N$ (prop-2-yn-1-yl)-2,3-dihydro- $1 H$-inden-1-amine (10) (10 g, $0.0584 \mathrm{~mol}, 1.0 \mathrm{eq})$, was taken in concentrated $\mathrm{HCl}(40 \mathrm{~mL})$ and were heated for $6 \mathrm{~h}$ at $60{ }^{\circ} \mathrm{C}$. The reaction was monitored by using TLC. After completion of the reaction, the reaction mixture was cooled to room temperature basified with aqueous $\mathrm{NH}_{3}$ solution and extracted with EtOAc dried and concentrated. The resultant crude was purified by column chromatography by using EtOAc and n-hexane as a mobile phase resulted $4.2 \mathrm{~g}$ compound $\mathbf{5}$ and $2.8 \mathrm{~g}$ compound $\mathbf{5 a}$.

Spectral data of compound 5: ${ }^{1} \mathrm{H}$ NMR $(400 \mathrm{MHz}$, DMSO); $\delta 7.66$ (d, 1H, Ar-H), 7.40-7.29 (m, 3H, Ar-H), 5.89$5.70\left(\mathrm{~d}, 2 \mathrm{H},=\mathrm{CH}_{2}\right), 4.85(\mathrm{~m}, 1 \mathrm{H}, \mathrm{NH}-\mathrm{CH}), 4.00(\mathrm{~m}, 2 \mathrm{H}, \mathrm{NH}-$ 
$\mathrm{CH}_{2}$ ), 3.17-2.85 (m, 2H, Ar- $\left.\mathrm{CH}_{2}\right), 2.49-2.15$ (m, 2H, CH-CH ${ }_{2}$. Mass: $m / z$ calcd. 207.08 , found $m / z 208.1\left(\mathbf{M}^{+1}\right)$. HPLC Purity (\%): 95.60 .

Spectral data of compound 5a: ${ }^{1} \mathrm{H}$ NMR $(400 \mathrm{MHz}$, DMSO); $\delta 7.66$ (d, 1H, Ar-H), 7.40-7.29 (m, 3H, Ar-H), 6.12 $(\mathrm{d}, 1 \mathrm{H},=\mathrm{CH}-\mathrm{Cl}), 5.58$ (d,1H.), $4.85(\mathrm{~m}, 1 \mathrm{H}, \mathrm{NH}-\mathrm{CH}), 4.00$ (m, 2H, NH-CH ), 3.17-2.85 (m, 2H, Ar- $\mathrm{CH}_{2}$ ), 2.49-2.15 (m, $\left.2 \mathrm{H}, \mathrm{CH}-\mathrm{CH}_{2}\right)$. Mass: $m / z$ calcd. 207.08, found $m / z 208.1\left(\mathrm{M}^{+1}\right)$.

\section{RESULTS AND DISCUSSION}

Numbers of routes are reported in the literature for the synthesis of rasagiline and its recemic compound [5-11]. Our synthesis commenced with commercially available 1-indanone (8) and $N$-(prop-2-yn-1-yl)-2,3-dihydro-1H-inden-1-amine (recemic compound) (10). 1-Indanone $(\mathbf{8})$ was converted to 1-indanamine (3) [12] followed by coupling with allyl bromide [13] resulted allyl impurity (4). On the other hand 1-indanone (8) was brominated [14] followed by coupling with propargylamine hydrochloride resulted keto impurity (7) with good yield (Scheme-I)
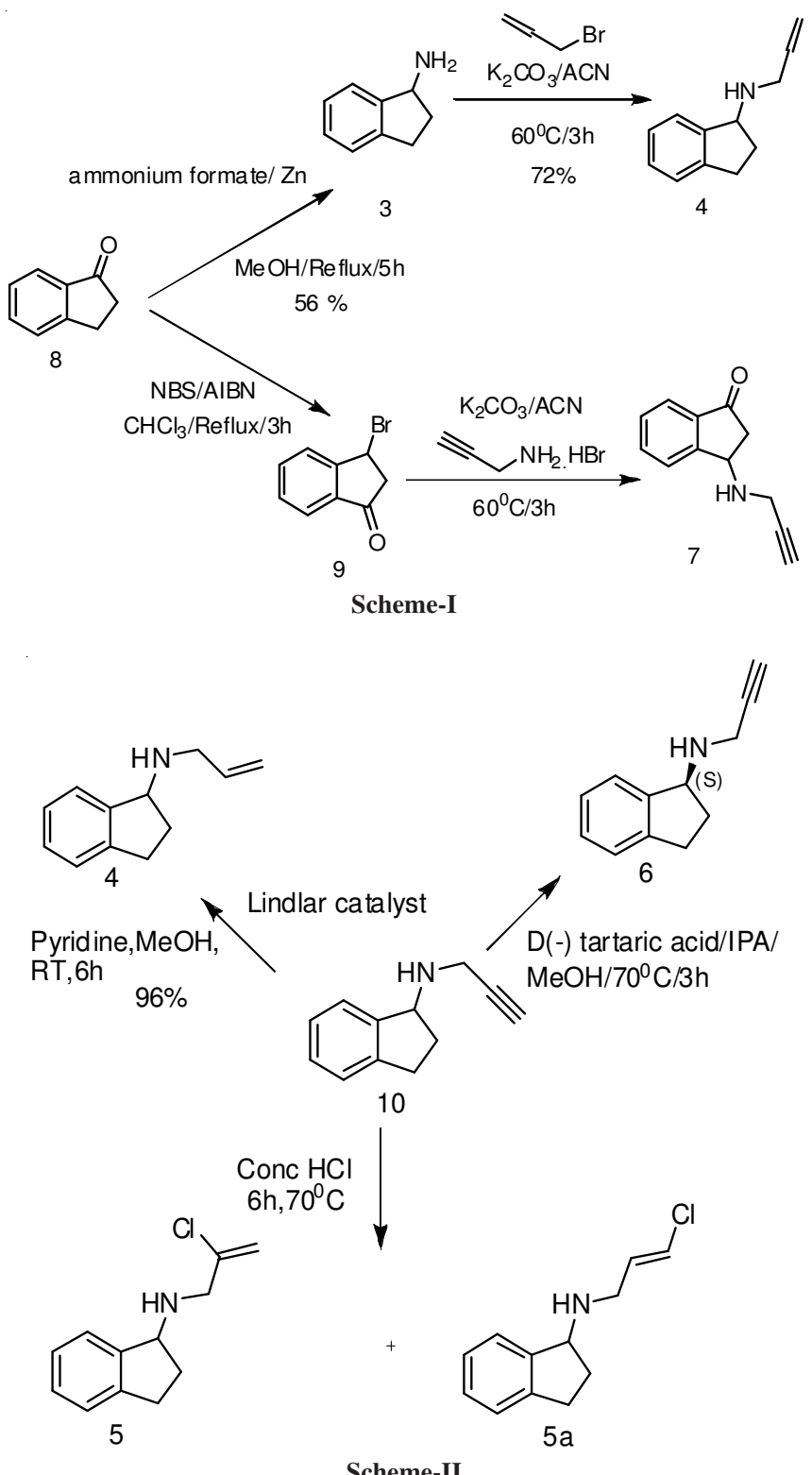

$N$-(prop-2-yn-1-yl)-2,3-dihydro-1 $H$-inden-1-amine (10) converted into allyl impurity (4) by using lindlar catalyst with good yield [15,16]. Markovnikov's and anti Markovnikov's addition of $\mathrm{HCl}$ on triple bond of compound $\mathbf{1 0}$ resulted compound $\mathbf{5}$ and compound $\mathbf{5 a}$. The recemic compound $\mathbf{1 0}$ was resoluted with $\mathrm{D}(-)$ tartaric acid resulted $99.7 \%$ chiral pure S-isomer (6) (Scheme-II).

\section{Conclusion}

In Scheme-I, allyl impurity (4) preparation, we are not achieved yield and purity (72\% by HPLC) and isolation problem was observed, followed Scheme-II with good yield and purity (90\% by HPLC). Similarly keto impurity, S-isomer and chloro ally impurity were prepared good yields.

\section{ACKNOWLEDGEMENTS}

The authors are thankful to the Management of Dr. Reddy's Laboratories Ltd, Hyderabad, India for providing facilities to carry out this work.

\section{REFERENCES}

1. Y. Akao, W. Maruyama, H. Yi, M. Shamoto-Nagai, M.B.H. Youdim and M. Naoi, Neurosci. Lett., 326, 105 (2002);

https://doi.org/10.1016/S0304-3940(02)00332-4.

2. F. Stocchi, C. Fossati and M. Torti, Expert Opin. Pharmacother, 16, 2231 (2015); https://doi.org/10.1517/14656566.2015.1086748.

3. I.N. Glazkov, N.L. Bochkareva and I.A. Revelskil, J. Anal. Chem., 60, 107 (2005) https://doi.org/10.1007/s10809-005-0003-3.

4. International Conference on Harmonization [ICH] Guidelines, Q3A [R] Impurities in New Drug Substances, February (2002).

5. M.B.H. Youdim, J.P.M. Finberg, R. Levy, J. Sterling, D. Lerner, T. BergerPaskin, H. Yellin and A. Veinberg, R-enantiomer of N-Propargyl-1-aminoindan, Salts, Compositions and Uses Thereof, US Patent US5532415 (1996).

6. A.L. Gutman, I. Zaltzman, V. Ponomarev, M. Sotrihin and G. Nisnevich, Process for the Preparation of Rasagiline and its Salts Patent, WO 200202068376 A1 (2002).

7. O.P. Goel, Process for the Resolution of 1-Aminoindanes, US Patent US4833273 (1989).

8. R. Levy, M.B.H. Youdim, J.P.M. Finberg, S. Cohen and J. Sterling, Pharmaceutical Compositions Comprising S-(-)-N-Propargyl-1-Aminoindan, US Patent US 6277886 B1 (2001).

9. M.B.H. Youdim, J.P.M. Finberg, R. Levy, J. Sterling, D. Lerner, T. BergerPaskin and H. Yellin, R-enantiomers of N-Propargyl-aminoindan Compounds, Their Preparation and Pharmaceutical Compositions Containing Them, US Patent US5457133 A (1995).

10. L.T. Boulton, I.C. Lennon and E. Bahar, Process for the Synthesis of Enantiomeric Indanylamine Derivatives, US Patent US7476757 B2 (2009).

11. M.W. Gittos, J.W. James and L.F. Wiggins, Methods of Lowering Blood Pressure in Animals by Administering Secondary and Tertiary Amines, US Patent US3513244 A (1970).

12. P. Falus, Z. Boros, G. Hornyánszky, J. Nagy, F. Darvas, L. Ürge and L. Poppe, Tetrahedron Lett., 52, 1310 (2011); https://doi.org/10.1016/j.tetlet.2011.01.062.

13. Patent WO2009/81148 A1 (2009).

14. L. Minuti, A. Taticchi, E. Gacs-Baitz and A. Marrocchi, Tetrahedron, 51, 8953 (1995); https://doi.org/10.1016/0040-4020(95)00504-2.

15. P. Macchi, W. Jing, R. Guidetti-Grept and R. Keese, Tetrahedron, 69, 2479 (2013); https://doi.org/10.1016/j.tet.2013.01.016.

16. Y. Arai, T. Kontani and T. Koizumi, Chem. Lett., 20, 2135 (1991); https://doi.org/10.1246/cl.1991.2135. 